\title{
A Spectral Model for the Study of the Atmospheric General Circulation I. Preliminary Long-Term Integration for the Terrestrial Atmosphere
}

\author{
By Tatsuya Iwashima*, Shigeru Moriyama** and Ryozaburo Yamamoto* \\ *Geophysical Institute, Kyoto University, Kyoto 606, Japan \\ **The Physical Science Laboratories, Nihon University at Narashino, \\ Funabashi, Chiba-ken 274, Japan \\ (Manuscript received 7 January 1978, in revised form 31 January 1979)
}

\begin{abstract}
A three-level linear-balance model for studies of the general circulation using the spectral method is presented with some preliminary results of time integration of the model for a specified terrestrial atmospheric condition.

The model is, firstly, integrated for 180 model days under a specified condition to obtain a quasi-steady state without eddies, starting from a calm atmosphere. The zonally symmetric state thus obtained is unstable for the disturbance with zonal wavenumber 5 or 6 , according to the linear theory of baroclinic instability. Secondly, after adding disturbances with small amplitudes to the above results of zonally symmetric model, the model integration is continued for another 180 model days to obtain a quasi-steady state with including eddies. The baroclinic instability appears to be released around the day 40 , and thereafter the near-equilibrium state is obtained. The results are illustrated mainly for the zonal mean field averaged during either the period of the last 100 days or that of release of baroclinic instability (the day 30-50), and for the time evolutions of energy components and energy conversion terms. The results are not necessarily realistic, because somewhat large values are used tentatively for a part of several parameters, such as the vertical eddy mixing coefficient. Nevertheless, reasonable results are obtained and they are consistent under the model assumption.

In order to study extensive problems concerning the general circulation and the climate of the planetary atmospheres, such a numerical model as is simple, economical and easy to handle is useful and worth-while to construct. So far as the preliminary results are concerned, we may say that the present model is one of powerful tools for further studies on the above subjects.
\end{abstract}

\section{Introduction}

The primary aim of this work is to construct such a numerical model of the atmospheric general circulation as is simple and easy to handle, but contains the essential processes in the largescale atmospheric flow, and is capable of long term stable integration. By using one of such models, we have been studying problems concerning both the climate of the terrestrial atmosphere and that of the Martian one, study of the effects of large-scale topography and heat sources due to large-scale land-sea distribution to maintenance of the ultra-long waves and so on. For this purpose we have performed a long term integration of the model with several simplified conditions and specified parameters. Some results of the integration will be shown here to illustrate the appropriateness of the model.

Recently several numerical models of the atmospheric general circulation tend to be larger and more complex with the higher resolution and sophisticated parameterization of the physical processes. Some complex models are important and necessary for more detailed simulation or forecasting of the real atmosphere. On the other hand, relatively simple models are needed for understanding the physical processes taking place in the actual atmosphere and the highly complex model atmosphere. Particularly, studies of the climate or atmospheric processes in a quasi-steady state demand us such a numerical model that is capable of long term time integration. Therefore, taking account of the computational and/or 
economical efficiency, we planned to construct a simple spectral linear-balance model with using the so-called spectral-grid transform method developed by Eliasen et al. (1970) and Orszag (1970). Use of the spectral-grid transform method easily enables us to introduce physical processes such as the radiative process and precipitation into the model.

This paper consists of the following sections: Section 2 is a description of governing equations of the model and boundary conditions. The numerical values of the parameters used in the model are given in section 3 . In section 4 the initial condition and some results of time integration are described. Section 5 gives a synoptic manifestation. In sections 6 and 7 we present some results of analyses of numerical integration, and compare them with those of the other models and of the observations. In section 8 concluding remarks are given. Appendices $\mathrm{A}$ and $\mathrm{B}$ are the list of symbols used in the present paper, and the energy equations in the spectral form, respectively. Appendix $\mathrm{C}$ is the results of an additional experiment in the case without taking account of the vertical eddy exchange term.

\section{Model}

We will use the governing equations in the following form, with pressure $p$ as the vertical coordinate, which is an energetically consistent system (Lorenz, 1960). We call the system the linear-balance model, because we linearize the non-linear Jacobian term in the balance equation. The notations of various symbols are summarized in Appendix A.

\subsection{Governing equations}

The governing equations are the vorticity equation, the thermodynamic equation and the thermal wind relation:

$$
\begin{aligned}
& \frac{\partial}{\partial t} \nabla^{2} \psi+J\left(\phi, \nabla^{2} \psi+f\right)+\nabla\left(\frac{f \nabla}{\partial p} \partial X\right)=F \\
& \frac{\partial}{\partial t} T+J(\phi, T)-\sigma\left(\frac{p}{p_{0}}\right)^{\kappa} \omega=\frac{\dot{Q}}{c_{p}} \\
& \frac{c_{p}}{p^{\kappa}} \nabla^{2} T=-\nabla \frac{\partial}{\partial p^{\kappa}}(f \nabla \phi)
\end{aligned}
$$

where $F$ in eq. (1) is the friction term, and is expressed as

$$
F=A_{M} \nabla^{2}\left(\nabla^{2} \psi+\frac{2}{a^{2}} \psi\right)-g \frac{\partial \tau}{\partial p}
$$

where

$$
\tau=-\rho \mu g \frac{\partial}{\partial p} \nabla^{2} \psi
$$

As the heating term in eq. (2) the following formulation may be adequate for our purpose:

$$
\frac{\dot{Q}}{c_{p}}=\frac{\dot{Q}_{\text {osb }}}{c_{p}}+A_{T} \nabla^{2} T
$$

where $\dot{Q}_{o b s}$ is the empirical non-adiabatic heating function, and the second term on the righthand side represents the effect of eddies with larger wavenumber than the truncated one. As $\dot{Q}_{o b s}$ the following generalized Newtonian heating and cooling expression is used:

$$
\frac{\dot{Q}_{\mathrm{obs}}}{c_{p}}=h\left(T^{*}-T\right)
$$

The values of the parameters in the above equations will be given in the later section.

As the upper boundary condition $\omega=0$ is used at the $100 \mathrm{mb}$ level. At the lower boundary both the topographic and Ekman pumping effects are introduced:

$$
\begin{aligned}
\omega & =-\rho_{0} g w=-\rho_{0} g J\left(\phi_{1}, H\right) \\
& -\rho_{0} g \frac{\sin 2 \alpha}{f} \sqrt{\frac{K_{v} f_{0}}{2}} \nabla^{2} \psi_{0}
\end{aligned}
$$

where $\alpha=22.5^{\circ}, K_{v}=10 \mathrm{~m}^{2} / \mathrm{sec}, f_{0}=10^{-4} \mathrm{sec}^{-1}$, and $\phi_{0}$ (the stream function at the lower boundary $\left.p=p_{0}\right)$ is assumed to be $0.5 \psi_{1}$.

\subsection{Transformation into the spectral form}

The dependent variables are represented by the coefficients of a truncated expression in the surface spherical harmonics as was done by Peng (1965), Clark (1970), Trenberth (1973), and others.

For simplicity we consider only the flow which is symmetric with respect to the equator, and has a scale comparable to the radius of the planet. Therefore, we will choose the following set of harmonics for the representation of the stream function $\phi$, the vertical $p$-velocity $\omega$ and the temperature $T$, respectively:

$$
\begin{aligned}
& \left\{Y_{1}{ }^{0}, Y_{3}^{0}, Y_{5}^{0}, Y_{m+1}^{m}, Y_{m+1}^{-m}, Y_{m+3}^{m},\right. \\
& \left.Y_{m+3}{ }^{-m} ; m=1,2,3,4,5,6\right\} \text { for } \phi,
\end{aligned}
$$

and

$$
\begin{gathered}
\left\{Y_{2}^{0}, Y_{4}^{0}, Y_{6}^{0}, Y_{m}^{m}, Y_{m}^{-m}, Y_{m+2}^{m}, Y_{m+2}{ }^{-m}\right. \\
m=1,2,3,4,5,6\} \text { for } \omega \text { and } T,
\end{gathered}
$$

where $Y_{n}{ }^{m}(\lambda, \phi)=P_{n}{ }^{m}(\sin \phi) \exp (\operatorname{im} \lambda)$ and $\boldsymbol{P}_{n}{ }^{m}$ $(\sin \phi)$ is the normalized associated Legendre function of the order $m$ and the degree $n$. 
The vertical resolution and the designation of the dependent variables on the pressure level are illustrated in Fig. 1. The dependent variables $\zeta\left(=\nabla^{2} \phi\right), \omega$ and $T$ at each level $j$ are expressed by the set of the above spherical harmonics:

$$
\begin{aligned}
\zeta_{j} & =\sum_{m=1,3,5} \zeta_{n, j^{0}} Y_{n}{ }^{0}+\sum_{m=1}^{6} \sum_{n=1,3}\left(\zeta_{n, j^{m}} Y_{n}{ }^{m}\right. \\
& \left.+\zeta_{n, j^{-m}} Y_{n}{ }^{-m}\right)
\end{aligned}
$$

for $j=1,3$ and 5 ,

$$
\begin{aligned}
\omega_{j} & =\sum_{n=2,4,6} \omega_{n, j^{0}} Y_{n}{ }^{0} \\
& +\sum_{m=1}^{6} \sum_{n=0,2}\left(\omega_{n}, j^{m} Y_{n}{ }^{m}+\omega_{n, j^{-m}} Y_{n}{ }^{-m}\right)
\end{aligned}
$$

for $j=0,2$ and 4 , and

$$
\begin{aligned}
T_{j} & =\left[\bar{T}_{j}\right]+\sum_{n=2,4,6} T_{n}, j^{0} Y_{n}{ }^{0} \\
& +\sum_{m=1}^{6} \sum_{n=0,2}\left(T_{n}, j^{m} Y_{n}{ }^{m}+T_{n}, j^{-m} Y_{n}{ }^{-m}\right)
\end{aligned}
$$

for $j=2$ and 4 , where $\left[\bar{T}_{j}\right]$ is a hemispherically averaged temperature at the $j$-th level. As the prescribed equilibrium temperature $T_{j}{ }^{*}$, we adopt the expansion similar to eq. (10) as

$$
\begin{aligned}
T_{j}^{*} & =\left[\bar{T}_{j}^{*}\right]+\sum_{n=2,4,6} T^{*}{ }_{n, j^{0}} Y_{n}{ }^{0} \\
& +\sum_{m=1}^{6} \sum_{n=0,2}\left(T_{n}, j^{m *} Y_{n}{ }^{m}+T_{n}, j^{-m *} Y_{n}{ }^{-m}\right)
\end{aligned}
$$

In order to ensure the real value of the expansion, we set the following form:

$$
\zeta_{n, j^{-m}}=\zeta_{n}, \overline{, j}^{m}, \quad \omega_{n, j^{-m}}=\overline{\omega_{n}, j^{m}},
$$

and

$$
T_{n, j^{-m}}=\overline{T_{n, j^{m}}}
$$

where an upper bar ( ) indicates the complex conjugate.

The derived spectral equations are represented as follows:

vorticity equation

$$
\begin{aligned}
& \frac{d}{d t} \zeta_{n, j^{m}}=-J Z_{n}, j^{m}+i b_{n}{ }^{m} \zeta_{n, j^{m}} \\
& \quad+(n-1) a_{n}, j^{m}\left(\omega_{n-1}{ }^{m}, j_{-1}-\omega_{n-1}{ }^{m}, j_{+1}\right) \\
& \quad+n a_{n+1}, j^{m}\left(\omega_{n+1}, j_{-1}{ }^{m}-\omega_{n+1}, j_{+1}\right)^{m} \\
& \quad-g_{n} \zeta_{n, j^{m}}-k_{j}\left(\zeta_{n, j}{ }^{m}-\zeta_{n, j-2}\right)^{m} \\
& \quad-k_{j}{ }^{\prime}\left(\zeta_{n}, j^{m}-\zeta_{n, j_{+2}}\right)^{m}
\end{aligned}
$$

for $m=0, n=1,3,5$; and $m=1,2,3,4,5,6$, $n=m+1, m+3 ; j=1,3,5$,

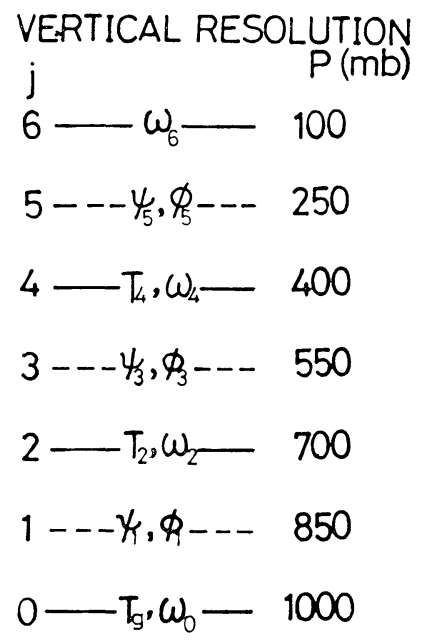

Fig. 1 Vertical resolution of the model.

where

$$
\begin{aligned}
& a_{n, j}{ }^{m}=\frac{2 \Omega}{\left(P_{j-1}-P_{j_{+1}}\right)} \frac{1}{n} \sqrt{\frac{(n+m)(n-m)}{(2 n+1)(2 n-1)}}, \\
& b_{n}^{m}=\frac{2 \Omega m}{n(n+1)}, \\
& g_{n}{ }^{m}=\frac{(n+2)(n-1)}{a^{2}} A_{M}, \\
& k_{j}=\frac{g^{2} P_{j_{-1}} \mu_{j_{-1}}}{R T_{j-1}\left(P_{j_{-2}}-\boldsymbol{P}_{j}\right)\left(\boldsymbol{P}_{j_{-1}}-\boldsymbol{P}_{j_{+}}\right)} \\
& k_{j}{ }^{\prime}=\frac{g^{2} \boldsymbol{P}_{j_{+1}} \mu_{j_{+1}}}{R T_{j_{+1}}\left(\boldsymbol{P}_{j}-\boldsymbol{P}_{j_{+}}\right)\left(\boldsymbol{P}_{j_{-1}}-\boldsymbol{P}_{j_{+1}}\right)}
\end{aligned}
$$

$J Z_{n},{ }_{j}{ }^{m}=$ the spherical expression of the vorticity Jacobian term,

$$
\zeta_{n,-1}^{m}=, \quad \zeta_{n, 7^{m}}=0 \quad \text { and } \quad \omega_{n, 6}{ }^{m}=0,
$$

thermodynamic equation

$$
\begin{gathered}
\frac{d}{d t} \boldsymbol{T}_{n, j^{m}}=-\boldsymbol{J} \boldsymbol{T}_{n, j^{m}}+\left(\frac{p}{p_{0}}\right)^{\kappa} \sigma_{j} \omega_{n, j^{m}} \\
-g^{\prime}{ }_{n}{ }^{m} \boldsymbol{T}_{n, j}{ }^{m}+\frac{1}{c_{p}} \dot{Q}_{n, j^{m}}
\end{gathered}
$$

for $m=0, n=2,4,6$; and $m=1,2,3,4,5,6$, $n=m, m+2 ; j=2,4$, where $J T_{n},{ }_{j}^{m}=$ the spherical expansion of the temperature Jacobian term, and

$$
g^{\prime}{ }_{n}{ }^{m}=\frac{n(n+1)}{a^{2}} A_{T} .
$$

thermal wind relation

$$
\begin{gathered}
T_{n, j^{m}}=\frac{a^{2}}{n} h_{n, j^{m}}\left(\zeta_{n-1, j-1}^{m}-\zeta_{n-1, j_{+1}}{ }^{m}\right) \\
+\frac{a^{2}}{n+1} h_{n+1, j}{ }^{m}\left(\zeta_{n+1, j-1} m-\zeta_{n+1}, j_{+1} m\right.
\end{gathered}
$$


for $m=0, n=2,4,6$; and $m=1,2,3,4,5,6$, $n=m, m+2 ; j=2,4$,

where

$$
\begin{aligned}
& h_{n},{ }^{m}=\frac{2 \Omega}{c_{p}} \frac{P_{j}^{k}}{\left(P_{j-1}{ }^{k}-P_{j+1}{ }^{k}\right)} \\
& \times \frac{1}{n} \sqrt{\frac{(n+m)(n-m)}{(2 n+1)(2 n-1)}}
\end{aligned}
$$

\section{Numerical values of the parameters}

Selection of the numerical values of the parameters in eqs. (13), (14) and (15) is made by referring to those of Trenberth (1973), Peng (1965), U.S. Standard Atmosphere Supplements (COESA, 1966), Kikuchi (1969), and WiinNielsen and Sela (1971). The hemispherically mean temperature $[\bar{T}]$ at the $700 \mathrm{mb}$ and $400 \mathrm{mb}$ levels and the stability parameter $\sigma$ at each level are tentatively assigned from the annual mean condition in the U.S. Standard Atmosphere Supplements. The lateral eddy viscosity coefficient $A_{M}$ and eddy-diffusion coefficient $A_{T}$ are assumed as follows:

$$
A_{M}=A_{T}=5 \times 10^{5} \mathrm{~m}^{2} / \mathrm{sec} \text {. }
$$

The vertical eddy viscosity coefficient $\mu$ is assumed to be inversely proportional to the static stability parameter $\sigma$ after Peng (1965);

$$
\mu_{2} \mu_{4}=1 / \sigma_{2}: 1 / \sigma_{4} \text {. }
$$

The time constant of Newtonian heating and cooling is assumed as follows:

$$
h_{2}=h_{4}=0.5 \times 10^{-6} \mathrm{sec}^{-1}
$$

at the $700 \mathrm{mb}$ and $400 \mathrm{mb}$ levels, being referred to Trenberth (1973), Peng (1965) and Robert (1966). The equilibrium temperature $T^{*}$ illustrated in Fig. 2 is obtained from the following assumption:

$$
T^{*}(\phi)=\left[\bar{T}^{*}\right]-A_{j}\left\{\sin 2\left(\phi-\phi_{0}\right)+\frac{1}{3}\right\}
$$

where $\phi_{0}=45^{\circ}$.

We tentatively specify the value of $A_{j}$ in the above function so that the temperature difference between the pole and the equator becomes about

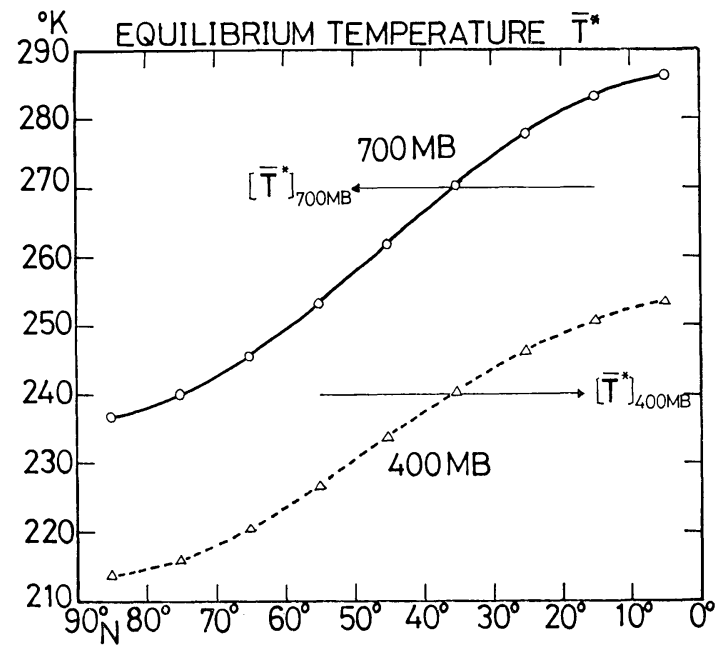

Fig. 2 Latitude distribution of the radiative equilibrium temperature.

$50^{\circ} \mathrm{K}$ at the $700 \mathrm{mb}$ level, and about $40^{\circ} \mathrm{K}$ at the $400 \mathrm{mb}$ level, by referring to the theoretical results of Manabe and Möller (1961): i.e., $A_{2}=$ $25^{\circ} \mathrm{K}$ at $700 \mathrm{mb}$, and $A_{4}=20^{\circ} \mathrm{K}$ at $400 \mathrm{mb}$.

The parameter adopted here are summarized in Table 1.

\section{Initial condition and time integration}

In this section described are the initial condition, the method of time integration, and the results concerning the zonal mean field and time variation of energy components.

\subsection{Initial condition}

The time integration is started from an isothermal atmosphere at rest and no eddies are added at the beginning stage. After the built-up period, disturbances with small amplitudes are added to the mean flow thus obtained. In addition we tentatively used the lower boundary condition that $\omega=0$, i.e., no topographic and surface effects.

\subsection{Method of time integration}

As the time integration scheme, we have

Table 1. Values of parameters used in the model.

\begin{tabular}{rrrcccc}
\hline $\mathrm{j}$ & $\mathrm{p}(\mathrm{mb})$ & $\sigma\left({ }^{\circ} \mathrm{K} / \mathrm{mb}\right)$ & $\mathrm{T}\left({ }^{\circ} \mathrm{K}\right)$ & $\mu(\mathrm{kg} / \mathrm{m} / \mathrm{sec})$ & $\mathrm{k}\left(10^{-6} \mathrm{sec}^{-1}\right)$ & $\mathrm{k}^{\prime}\left(10^{-6} \mathrm{sec}^{-1}\right)$ \\
\hline 0 & 1000 & & 294 & 22.5 & & \\
1 & 850 & & & & 2.845 & 2.17 \\
2 & 700 & 0.0357 & 270 & 22.5 & 2.17 & 0.626 \\
3 & 550 & & & & & \\
4 & 400 & 0.0798 & 240 & 10.1 & 0.626 & 0 \\
5 & 250 & & & & & \\
6 & 100 & & & & & \\
\hline
\end{tabular}


chosen the centered difference method after Kikuchi (1969) with using the forward difference periodically (every 30 time steps) in order to prevent the computational instability.

The non-linear Jacobian terms in the governing equations (13) and (14) [i.e., $J Z_{n}, j^{m}$ in eq. (13), and $J T_{n}, j^{m}$ in eq. (14)] are calculated by using the spectral-grid transform method. We used the 64 Gaussian latitudes and 24 longitude points.

\subsection{Preliminary time integration excluding eddies and resultant zonally symmetric steady state}

Starting from a calm condition, we integrated the governing equations numerically for 180 model days with the time increment $\Delta t=1$ day, excluding eddies. Fig. 3 shows the time evolution of energy components $K Z, A Z$ and $A Z+K Z$. According to this figure, a nearly steady state is observed at the last days of integration. Fig. 4 illustrates the latitude-height distribution of the results at the day 180 . The temperature difference between the equator and the pole is reduced to about $30^{\circ} \mathrm{K}$, compared with that in the radiative equilibrium $\left(50^{\circ} \mathrm{K}\right.$ in Fig. 2). According to both the latitude-height distributions of the meridional motion and vertical $p$-velocity, a direct cell of Hadley type is visualized as is expected, and the region of the upward motion is narrower than that of the downward one. The meridional temperature gradient in middle latitudes and the corresponding maximum westerly are small in comparison with the observation.

\subsection{Time integration including eddies}

According to the linear baroclinic instability

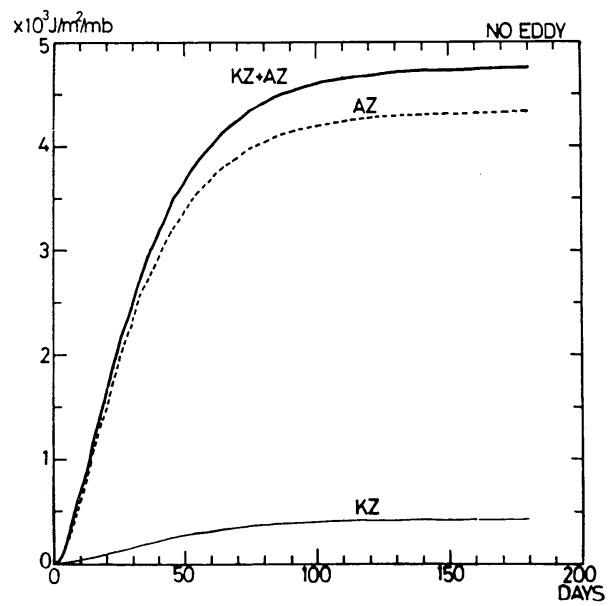

Fig. 3 Time evolution of energy components $\mathrm{KZ}, \mathrm{AZ}$ and $\mathrm{AZ}+\mathrm{KZ}$ during the preparatory integration.
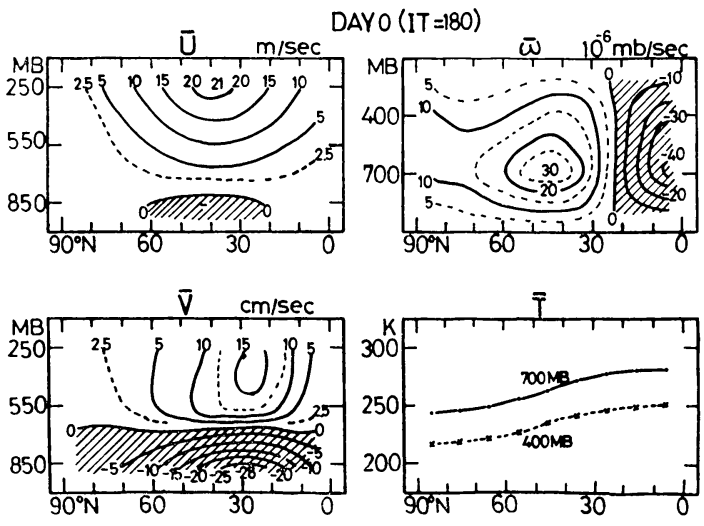

Fig. 4 Latitude-height distributions of the zonal mean fields of $\bar{U}, \bar{v}, \bar{\omega}$ and $\bar{T}$ at the end of the preparatory integration (the day 180).

theory of Phillips (1954), the zonally symmetric field obtained above is unstable for the disturbances with wavenumber 5 or 6 . The theoretical growth rates of disturbances are, however, small and that of wavenumber 5 is larger than wavenumber 6 .

After adding the disturbances with small amplitudes to the mean flow obtained at the end of the preliminary integration (Fig. 4), we continued the time integration up to another 180 model days.* The initial disturbances, whose spectral distributions of kinetic and available potential energies are given in Fig. 5, have the kinetic and available potential energies by the magnitude of

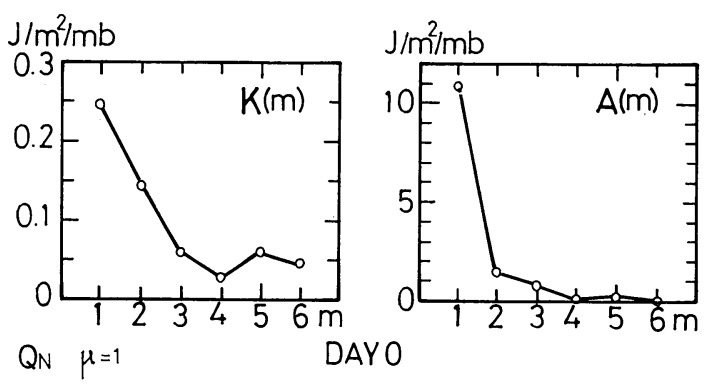

Fig. 5 Spectral distributions of eddy energies initially added to the zonal mean state in Fig. 4.

*) Computation of the model which consists of five zonal wavenumbers $(m=0,1,2,3$ and 6$)$ took $0.47 \mathrm{sec}$ per a time interval $\Delta t$ of CPU time on our university's computer (FACOM M-190; average instruction execution time $=0.16 \mathrm{~s}$ ); for the model of seven wavenumbers $(m=0,1,2,3,4$, 5 and 6) the calculation time increased to 0.75 sec per a time interval. 


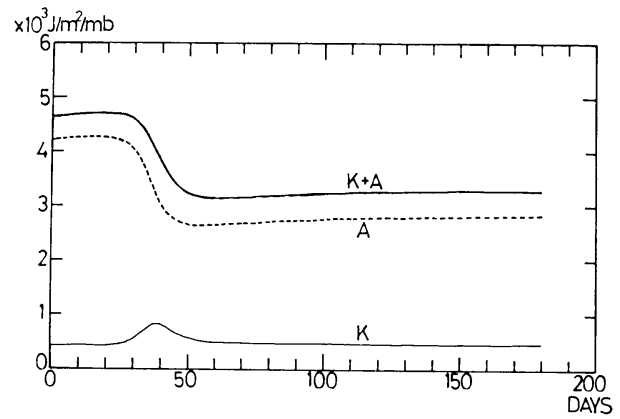

Fig. 6 Time evolution of total $(A+K)$, available (A) and kinetic (K) energies.

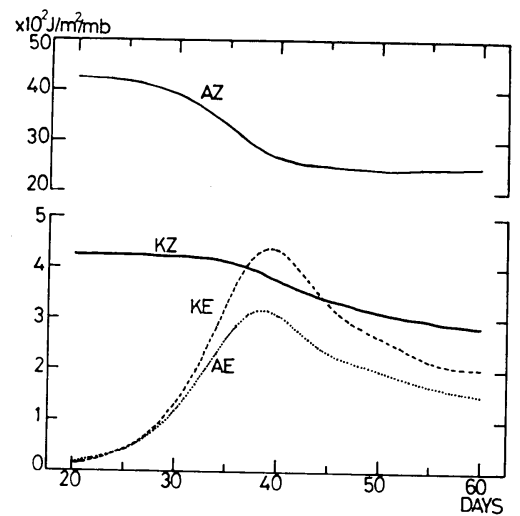

Fig. 7 Time evolution of the zonal and eddy energy components, $\mathrm{AZ}, \mathrm{KZ}, \mathrm{AE}$ and $\mathrm{KE}$, during the $\mathrm{BI}$ stage.

about 0.1 and $0.3 \%$ of the corresponding zonal mean energies, respectively.

We obtained the time variation of total energy $(\mathrm{A}+\mathrm{K})$ and energy components ( $\mathrm{A}$ and $\mathrm{K}$ ) during the course of integration in Fig. 6. The following features are noted: At the beginning, the decrease of $\mathrm{A}$ and $\mathrm{A}+\mathrm{K}$, and the corresponding increase of $\mathrm{K}$ around the day 40 are evidently observed, and then $\mathrm{A}$ and $\mathrm{K}$ slowly approach to a steady state without fluctuations. Finally, the kinetic energy $\mathrm{K}$ is reduced to the initial energy level, and the available potential energy A becomes about $70 \%$ of the initial value. The rapid changes of energy components around the day 40 is speculated as the release of the baroclinic instability. The speculation is more clearly supported in Fig. 7 where shown are the zonal and eddy energy components during the period from the day 20 to 60 . The feature similar to this is seen in the results by other investigators, e.g., Hunt (1974). In contrast to the Hunt's case, the energy $\mathrm{A}$ in the present case does not recover to its initial level within the period of integration up to the day 180 .

In order to investigate in more detail, we will show the results of the following two stages in the next section: the stage in which disturbances developed due to the baroclinic instability during the period from the day 30 to 50 (stage BI) and the stage in a quasi-steady state during the last 100 days of the integration (stage QS).

\section{Synoptic manifestation}

In this section several maps of the geopotential height and temperature will be illustrated for the sake of qualitative comparison. Fig. 8 shows the height field at the $550 \mathrm{mb}$ level and the temperature field at the $400 \mathrm{mb}$ level of every 5 th day from the day 30 to 50 . The development of disturbances due to the release of the baroclinic instability for wavenumbers 5 and 6 is seen in these maps. They evidently illustrate the predominance of wavenumber 6 in subtropical latitudes. Needless to say, the detailed feature in middle latitudes in the actual atmosphere can be hardly simulated in the present model except several characteristic ones, because of the limited freedom in the zonal and meridional wavenumber space. The centers of the cyclone are located around $35^{\circ}-45^{\circ} \mathrm{N}$ and those of the anticyclone $25^{\circ}-35^{\circ} \mathrm{N}$. Disturbances move eastward with the phase speed of about $12^{\circ}$ longitude/day, which is rather smaller than that in the real atmosphere. The following two supplementary experiments, however, show that the calculated phase speed is acceptable: In the first experiment by using the Haurwitz wave as the initial condition like Phillips (1959), the phase speed of wavenumber 6 is about $24^{\circ}$ longitude/day, compared with his theoretical estimate of $23.6^{\circ}$ longitude/day. In the second experiment which was conducted to see the influence on the model of the vertical eddy mixing (see Appendix C), the phase speed is about $15^{\circ}$ longitude/day.

\section{Time mean for the quasi-steady stage (QS)}

As is shown in the previous section, the quasisteady state is achieved after the release of the baroclinic instability. In this section the time mean averaged over the period from the day 80 to 180 is described.

\subsection{Zonal mean field}

Fig. 9 shows the latitude-height distribution of the zonal mean quantities; the mean of zonal wind $\bar{u}$, temperature $\bar{T}$ and vertical $p$-velocity $\bar{\omega}$. 

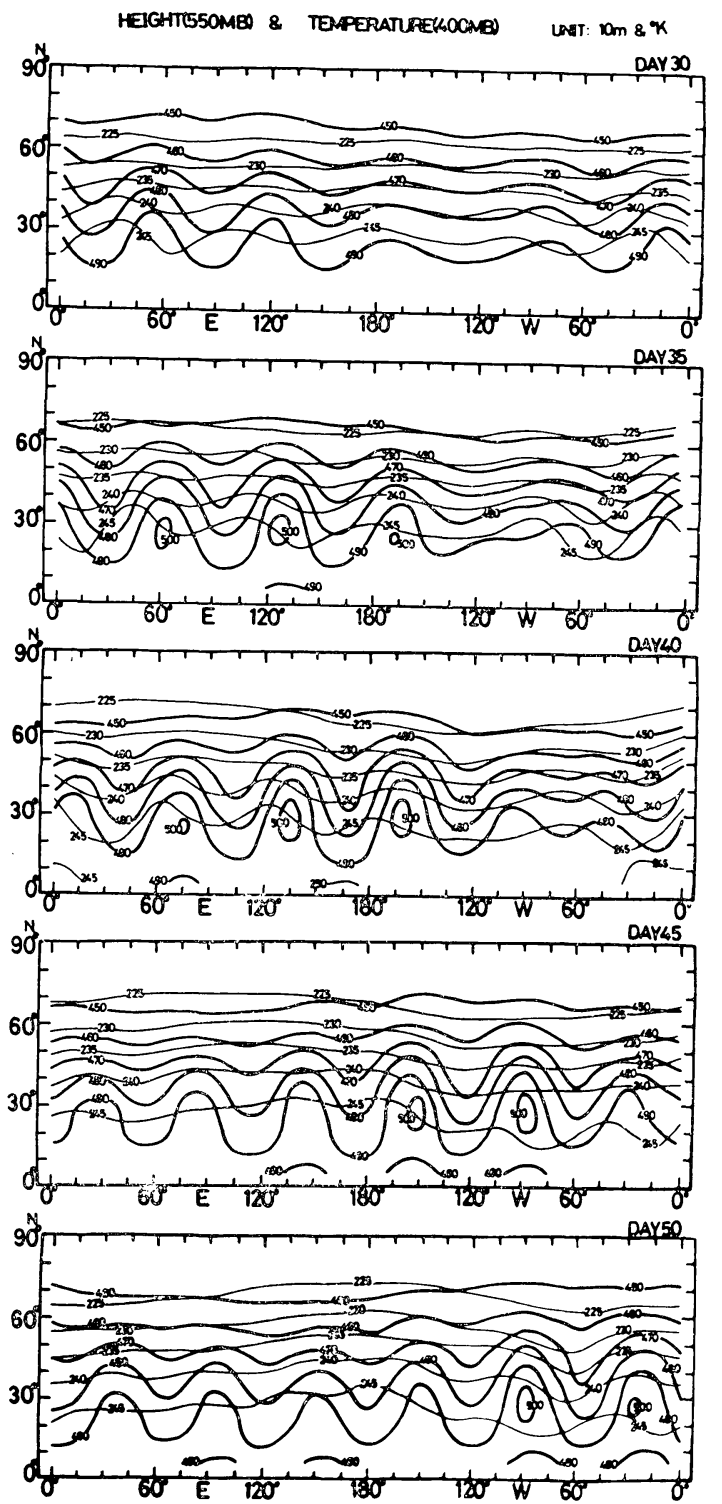

Fig. 8 Synoptic maps of height $(550 \mathrm{mb})$ and temperature $(400 \mathrm{mb})$ fields of every 5 th day during the course of the BI stage.

The temperature difference between the equator and the pole has decreased by only a few degrees Kelvin, in comparison with the initial stage (Fig. 4). At the same time the westerly maximum wind has decreased by a few meters per second. A three-cell like distribution is noted in the latitudeheight distribution of $\bar{\omega}$, which is caused by introduction of eddies. The magnitude of disturbances is, however, rather small, and the indirect cell in middle latitudes is not so strong as to cause southward and northward motions at upper
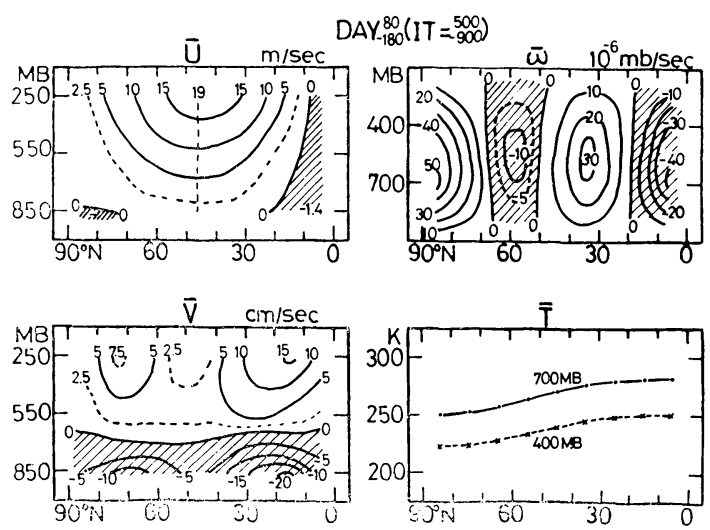

Fig. 9 Latitude-height distribution of the zonal mean fields of $\bar{U}, \bar{v}, \bar{\omega}$ and $\bar{T}$ for the QS stage (averaged over the period from the day 80 to 180 ).

and lower levels, respectively. At the stage of the release of the baroclinic instability, disturbances develop as will be shown in the next section. In addition, taking account of a theoretical study of Arakawa (1957), we may infer that one of the causes of weakness of the indirect cell is resulted from the use of a large value as the vertical eddy mixing coefficient in the friction term*. The large frictional term will affect to the distribution of the mean zonal wind as was pointed out by Stone et al. (1974) and Tenenbaum (1976). The experiment of Searle and Davies (1975) suggests that the structure and eddy kinetic energy of disturbances are sensitive to the magnitude of vertical eddy viscosity. The above statements were confirmed by an additional test where the vertical eddy mixing coefficient was assumed to be zero. Some of the results of the numerical integration are given in Appendix $\mathrm{C}$.

*) Based on the assumption that the atmosphere is adiabatic and frictionless, Arakawa (1957) gave the expression of the stream function $\Psi$ of the mean meridional circulation as follows:

$$
\Psi=-\frac{\overline{v^{\prime}} \overline{\theta^{\prime}}}{\partial \theta / \partial p} \cos \phi+\int_{0}^{p} \frac{F_{\lambda}}{\eta} \cos \phi d \pi
$$

where the bar $(\overline{)}=$ the zonal mean; the prime ()$^{\prime}=$ the deviation from the zonal mean; $v=$ meridional velocity; $\theta=$ potential temperature; $F_{\lambda}=$ zonal component of the frictional force; $\eta=$ absolute vorticity $=f+\zeta ; \int(\quad) d \pi=$ the integration with respect to $p$ along the isoline of $(f a \sin \phi / 2)-\bar{U} \cos \phi$. In the above expression the positive and negative signs of $\Psi$ mean the indirect and direct circulations, respectively. 


\subsection{Distribution of eddy kinetic energy}

Fig. 10 illustrates the latitude-height distribution of eddy kinetic energy. The maximum value is seen in the upper level southward of the westerly maximum wind. The rather large values are concentrated in the subtropical latitudes, and the values distributed in middle latitudes are one or two order of magnitude smaller than those of the observation. In comparison with annual mean values in the real atmosphere [e.g., Peixoto and Oort (1974)], the calculated values are much too small. These quantitative discrepancy seems to be due to the fact that the ultra-long waves are not so fully simulated in the present model, as is shown in Fig. 11 of the spectral distribution of the kinetic energy.

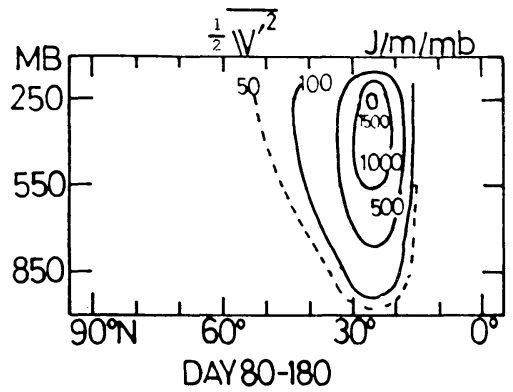

Fig. 10 Latitude-height distribution of eddy kinetic energy.

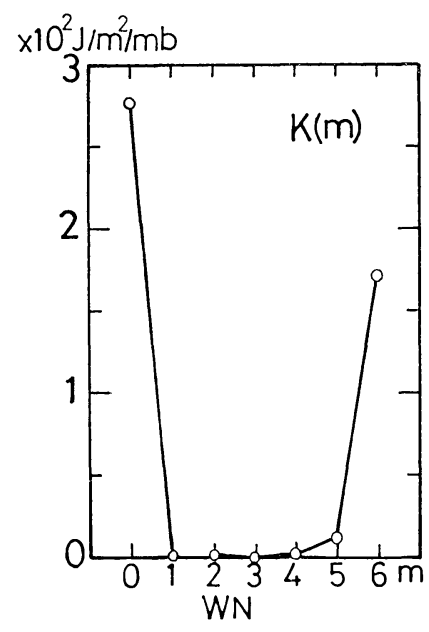

QN $\mu=1 \quad$ DAY 80-180

Fig. 11 Spectral distribution of kinetic energy for the QS stage.

\subsection{Eddy transport of momentum and sensible heat}

The latitude-height distribution of the poleward eddy transport of westerly momentum is given in Fig. 12. In comparison with the observational annual mean values [e.g., Oort and Rasmusson (1971)], we note the following points: i) The maximum of eddy momentum flux is located at the subtropics in the upper level, and its value is much smaller than the observational one (about $30 \%$ ). ii) In the lower levels in middle and high latitudes, the eddy momentum flux is small and negative, which means the southward transport of westerly momentum. The value integrated vertically is much smaller than the observational value. Fig. 13 is the latitude-height distribution of the poleward eddy transport of sensible heat. The following points are noted: i) The maximum value appears around $30^{\circ} \mathrm{N}$, which is lower by about $20^{\circ}$ latitude compared with the annual mean observational results. ii) The heat transport is larger in the lower level than in the upper level, even though the two maxima of the high and low levels as are seen in the actual atmosphere cannot be realized in the model.

Taking account of the observational results by Wiin-Nielsen et al. (1964), who separated the heat and momentum transports into two groups, i.e., that due to the ultra-long waves and to long waves, we may speculate that the discrepancies between the model and the observation mentioned

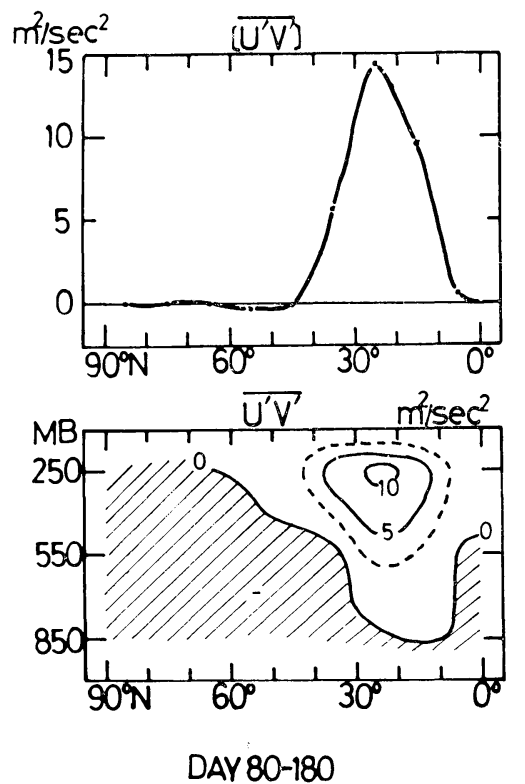

Fig. 12 Latitude-height and meridional distribution of eddy poleward transport of westerly momentum for the QS stage. 

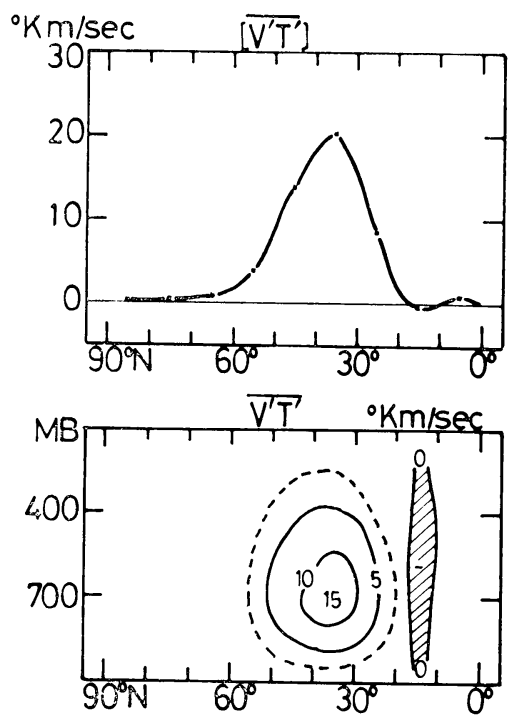

Fig. 13 Same as Fig. 12, except for the sensible heat.

above are caused by the insufficient simulation of the ultra-long waves owing to the lack of their energy sources.

\subsection{Energy balance}

Fig. 14 is the energy box diagram showing the mean and eddy energies and their transformations for the period of the day 80 to 180 . Qualitative$1 y$, the energy cycle of the model is consistent with that of the real atmosphere, i.e., the direction of energy flow agrees with the annual mean observational results. There are, however, the following quantitative discrepancies: The zonal energy components $\mathrm{AZ}$ and $\mathrm{KZ}$ are $70 \sim 80 \%$, and $\mathrm{KE}$ is about $20 \%$, in comparison with the respective observed value. The value of $\mathrm{AE}$ in the present result is much smaller (about 1\%)

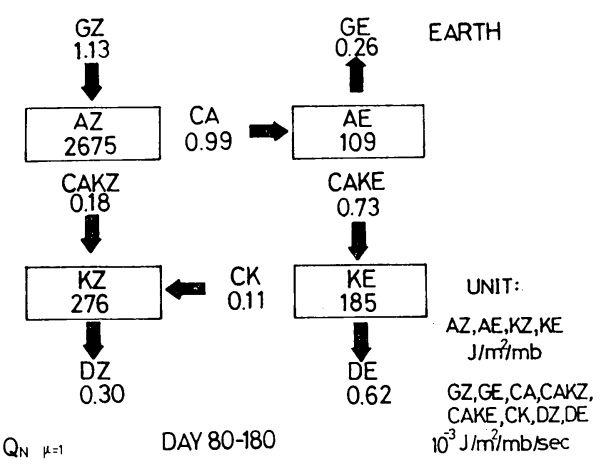

Fig. 14 Energy flow diagram for the QS stage. than that in the real atmosphere. The energy generation, dissipation and transform terms, GZ, GE, CA, CAKE, CK and DE, except CAKZ and $\mathrm{DZ}$, are less than a half of the respective observed value, and the $\mathrm{DZ}$ term is $75 \%$ of the observed one. A main cause of these discrepancies may be attributed to the absence of developed ultralong waves, as is seen in Fig. 11 of the spectral energy distribution for the QS state.

\section{Time mean over the period of eddy developing (BI)}

In this section the time evolution of energy components during the period of eddy developing due to the baroclinic instability is illustrated, and only the notable results are described regarding the time mean quantities at the BI stage.

\subsection{Time evolution of energy components and energy transformation terms}

Fig. 15 shows the time variation of eddy kinetic energy $\mathrm{KE}$ and its components of wavenumbers 5 and 6 . The disturbance of wavenumber 5 is more unstable than that of wavenumber 6 , as is predicted from the linear theory of the baroclinic instability by Phillips (1954). During the period from the day 30 to 50 , total kinetic energy $\mathrm{K}(=\mathrm{KZ}+\mathrm{KE})$ is dominant. Since such a time lag between both periods is not so large, the time averaging at the BI stage is operated for the same 20 days of the period of the day $30-50$.

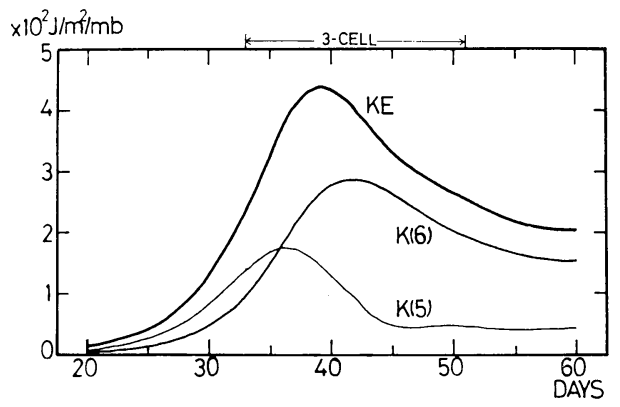

Fig. 15 Time variation of eddy kinetic energy $\mathrm{KE}$ and its main spectral components of wavenumber 5 and 6 during the period from the day 20 to 60 including the BI stage.

The variation of energy conversion terms CAKE, CAKZ, CA and CK are illustrated in Fig. 16. From this figure the following points are seen:

i) The energy transfer and conversion terms $\mathrm{CA}$ and CAKE are dominant after the day 30. 


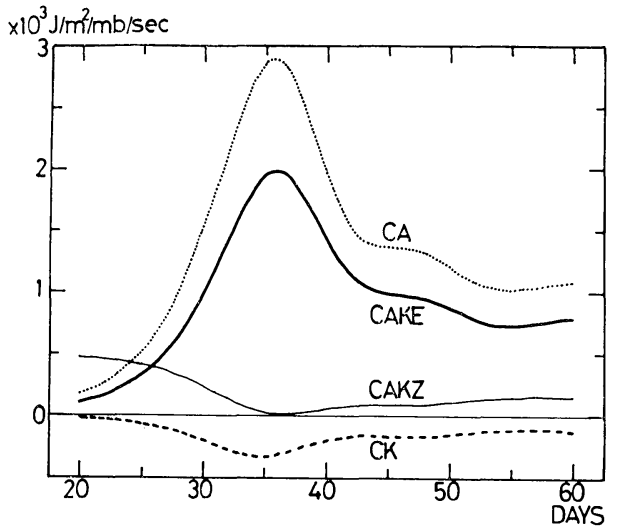

Fig. 16 Time variation of various energy conversion or transform terms.

ii) The temporal trend of the energy transfer and conversion terms CA, CAKE, CAKZ and $\mathrm{CK}$ corresponds to that of $\mathrm{KE}$. iii) The term of barotropic transfer process $\mathrm{CK}$ is small, compared with CA and CAKE. Considering the studies by Simmons and Rao (1972) and Simmons and Hoskins (1978), we may mention that the small magnitude of CK is partly due to the limited number of the meridional modes in our model.

\subsection{Zonal mean field}

At the stage BI, most quantities increase relative to those at the remaining stages. Main qualitative difference appears in the latitudeheight distribution pattern of the zonal mean field, especially in the meridional circulation. As is shown in the former section (Fig. 9), the indirect cell in the middle latitudes is not seen at the QS stage. In marked contrast to this, the three-cell pattern of meridional circulation clearly appears at the BI stage from the day 33 to 51 . Fig. 17 illustrates the latitude-time sections of the mean meridional velocity at the $250 \mathrm{mb}$ and 850 $\mathrm{mb}$ levels. We can see the appearance of a definite three-cell pattern as eddies develop. As is shown in Fig. 18, the three-cell structure is also seen in the latitude-height distribution of the zonal mean quantities averaged over the period of the day 30 to 50 .
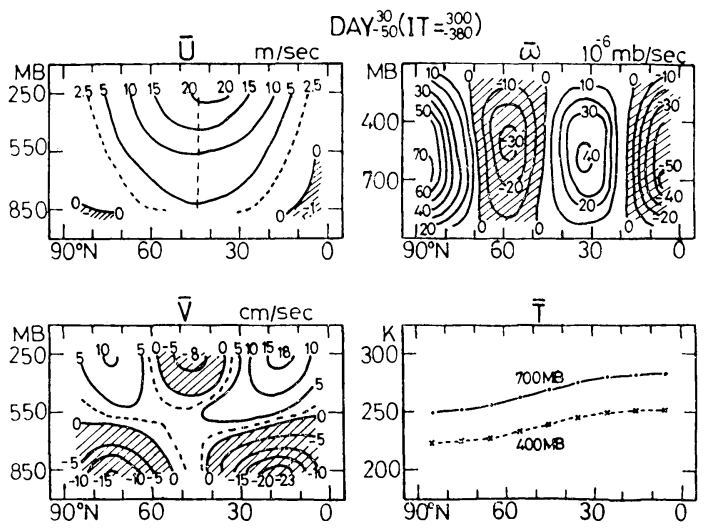

Fig. 18 Same as Fig. 9, except for the BI stage during the period from the day 30 to 50 .
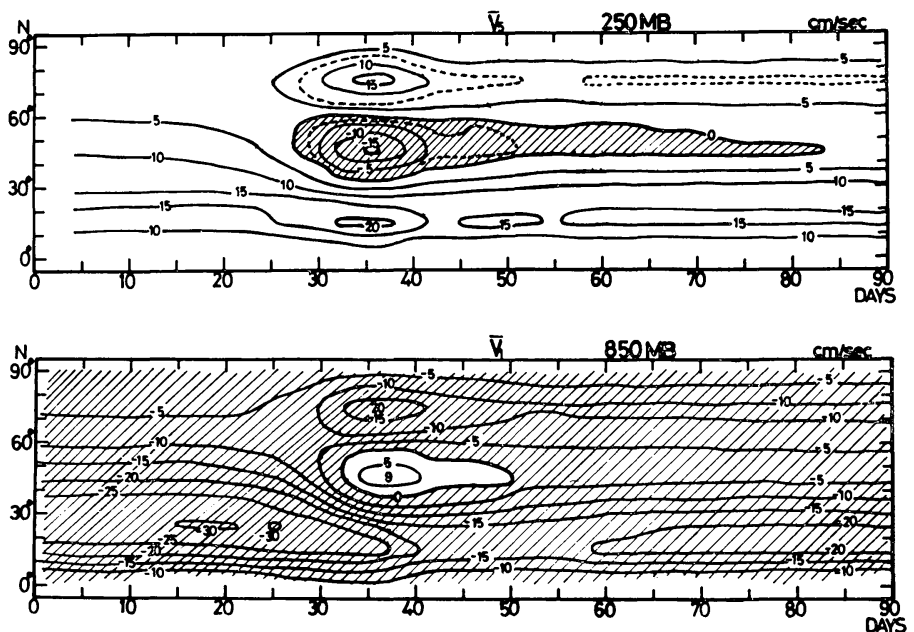

Fig. 17 Latitude-time sections of mean meridional velocity $\bar{v}$ at the $250 \mathrm{mb}$ and $850 \mathrm{mb}$ levels, respectively. The shaded area shows the southward motion. Unit is $\mathrm{cm} / \mathrm{sec}$. 


\subsection{Energy balance}

Fig. 19 denotes the energy flow diagram for the period of the day 30 to 50 . The eddy energies and eddy energy transformation are about two times as large as those at the QS stage. On the other hand, the zonal mean quantities, i.e., AZ, $\mathrm{KZ}$ and CAKZ are close to those at the QS stage, mainly due to weakness of the direct cell and/or appearance of the indirect cell.

Concerning the distributions of eddy kinetic energy and eddy transports of momentum and sensible heat, there are no qualitative differences between two stages. Quantitatively, however, those quantities at the BI stage have a magnitude by about one and a half to two times as large as those at the QS stage.

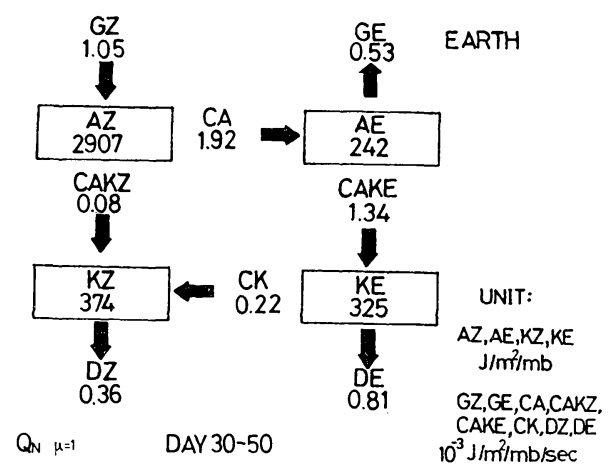

Fig. 19 Same as Fig. 14, except for the BI stage.

\section{Concluding remarks}

In this paper we have presented the linear balance general circulation model based on the spectral method, together with some results of the numerical time integration for a specified terrestrial condition. As stated in the introduction, the main purpose of the present paper is to illustrate the capability of long-term stable integration of the model, and the outlook on constructing a more complicated model for the general circulation and climate studies. In order to examine the characteristics of the model, a few preliminary long term integrations were performed and the results of analysis were compared with the observations, concerning the latitudeheight distributions of zonal mean quantities such as eddy transports of momentum and sensible heat, and the energetics. In comparison with the observed values, there are several remarkable discrepancies. Namely, in the model atmosphere, the meridional circulation is a single cell of the Hadley type, the magnitudes of eddies are small, and the northward eddy transports of momentum and sensible heat become maximum at the subtropical latitudes. These discrepancies may be attributed to the following two reasons: One is considered due to the lack of energy sources for the ultra-long waves. Another reason is the large value of the vertical eddy-viscosity coefficient employed in the present model. The supplementary experiment suggests that the above speculation would be reasonable. We may, therefore, conclude that the present model can well be usable as a simple, economical and easy-tohandle tool for extensive studies of the general circulation and the climate of the planetary atmospheres. We may proceed as a next step to construct a more complicated model.

In the subsequent paper, we will more closely examine some factors of generation and control of the ultra-long waves, such as the topography and the non-adiabatic heating of the global scale.

\section{Acknowledgements}

The authors wish to thank Dr. Takashi Nitta and reviewers for their helpful advice. The computations were performed with use of the computer at the Data Processing Center of Kyoto University (Job Nos. 5001HA741, 5001KA842, BJA0405, AKB0508, BGB1577, BHB1784, BAC 1998 and BPC2581). This work is financially supported by a scientific fund from the Ministry of Education.

\section{Appendix A: List of symbols}

$a:$ radius of the earth,

$f:$ Coriolis parameter $=2 \Omega \sin \phi$

$g:$ acceleration of gravity

$h:$ time constant for Newtonian cooling and heating term

$p:$ pressure

$t:$ time

$v:$ meridional velocity

$w$ : vertical velocity

$A_{M}$ : lateral kinematic eddy-viscosity coefficient

$A_{T}$ : lateral eddy-diffusion coefficient for heat

$c_{p}$ : specific heat of dry air at constant pressure

$F:$ frictional term per unit mass of air

$H$ : topographic height

$J(\quad)$ : Jacobian operator,

$$
J(A, B)=\frac{1}{a^{2} \cos \phi}\left(\frac{\partial A \partial B}{\partial \lambda \partial \phi}-\frac{\partial B \partial A}{\partial \lambda \partial \phi}\right)
$$

$J T:$ Jacobian term of temperature advection $J Z$ : Jacobian term of vorticity advection 
$K_{v}$ : kinematic eddy viscosity coefficient $=10 \mathrm{~m}^{2} / \mathrm{sec}$

$\boldsymbol{P}_{n}{ }^{m}=\boldsymbol{P}_{n}{ }^{m}(\sin \phi):$ normalized associated

Legendre function of the order $m$ and the degree $n$

$\dot{Q}$ : non-adiabatic heating term

$R$ : gas constant for dry air

$T:$ temperature

$T^{*}:$ imposed equilibrium temperature

$X=\int_{0}^{p} \chi d p$

$Y_{n}^{m}(\lambda, \phi)=\boldsymbol{P}_{n}^{m}(\sin \phi) \exp (\operatorname{im} \lambda)$

$\alpha$ : cross-isobar flow angle $=22.5^{\circ}$

$\nabla:$ horizontal gradient operator

$$
=\boldsymbol{i} \frac{1}{a \cos \phi \partial \lambda}+\boldsymbol{j} \frac{\partial}{a \partial \phi}
$$

$\zeta$ : vertical component of relative vorticity $=\nabla^{2} \psi$

$\kappa=R / c_{p}$

$\lambda:$ longitude

$\mu$ : small scale vertical eddy-viscosity coefficient

$\psi:$ stream function

$\rho:$ air density

$\sigma:$ static stability parameter $=-\partial[\bar{\theta}] / \partial p$

$\phi$ : latitude

$\theta:$ potential temperature

$\omega:$ vertical $p$-velocity $=d p / d t=\nabla^{2} \chi$

$\Omega$ : angular velocity of the earth

$\chi:$ velocity potential $=\partial X / \partial p$

( ) : zonal mean $=\frac{1}{2 \pi} \int_{0}^{2 \pi}(\quad) d \lambda$

()$^{\prime}$ : deviation from zonal mean $=(\quad)-(-)$

[-]: area mean over the Northern Hemisphere

$A:$ total available potential energy

$$
=\mathrm{AZ}+\mathrm{AE}
$$

$A(m)$ : wavenumber $m$ component of eddy available potential energy

$A E:$ eddy available potential energy $=\sum_{m} A(m)$

$A Z$ : zonal available potential energy

$K:$ total kinetic energy $=\mathrm{KZ}+\mathrm{KE}$

$K(m)$ : wavenumber $m$ component of eddy kinetic energy

$K E$ : eddy kinetic energy $=\sum_{m} K(m)$

$K Z$ : zonal kinetic energy

$C A$ : transfer from $\mathrm{AZ}$ to $\mathrm{AE}$

$C K$ : transfer from $\mathrm{KZ}$ to $\mathrm{KE}$

$C A K E$ : conversion from $\mathrm{AE}$ to $\mathrm{KE}$

$C A K Z$ : conversion from $\mathrm{AZ}$ to $\mathrm{KZ}$

$D Z$ : viscous dissipation term of $\mathrm{KZ}$
$D E$ : viscous dissipation term of $\mathrm{KE}$

$G Z$ : generation term of $\mathrm{AZ}$

$G E$ : generation term of $\mathrm{AE}$

$B K Z$ : flux of the zonal kinetic energy $\mathrm{KZ}$ through the lower boundary

$B K E$ : Same as BKZ, except for the eddy kinetic energy $\mathrm{KE}$

$L K(m)$ : transfer of kinetic energy between wavenumber $m$ and all other waves

$L A(m)$ : transfer of available potential energy between wavenumber $m$ and all other waves

\section{Appendix B: Governing equations and definitions of energy transformations used for the model energetics}

The total, zonal and eddy kinetic energies averaged over the whole hemisphere are given by the following relations:

$$
\begin{aligned}
& K=K Z+K E \\
& K Z=\sum_{j=1,3,5} \frac{H_{j}}{2} \sum_{n} n(n+1) \phi^{0}, j^{2} \\
& K(m)=\sum_{j=1,3,5} H_{j} \sum_{n} n(n+1) \phi_{n}, j^{m} \psi_{n, j} m * \\
& K E=\sum_{m} K(m)
\end{aligned}
$$

where

$$
H_{j}=\frac{1}{g} \frac{P_{j_{-1}}-P_{j_{+1}}}{\sum_{j}\left(P_{j_{-1}}-P_{j_{+1}}\right)}
$$

The total, zonal and eddy available potential energies are given as follows:

$$
\begin{aligned}
& A=A Z+A E \\
& A Z=\sum_{j=2,4} \frac{G_{j}}{2} \sum_{n} T^{0} n_{, j}{ }^{2} \\
& A(m)=\sum_{j=2,4} G_{j} \sum_{n}\left|T_{n}, j^{m}\right|^{2} \\
& A E=\sum_{m} A(m)
\end{aligned}
$$

where

$$
G_{j}=\frac{c_{p} P_{0}^{k}\left(P_{j_{-1}}-P_{j_{+1}}\right)}{g P_{j}^{2 k} \sum\left(P_{j_{-1}}-P_{j_{+1}}\right) \sigma_{j}}
$$

The governing equations of the kinetic and available potential energies in zonal and eddy forms are as follows:

$$
\begin{aligned}
& \frac{\partial K Z}{\partial t}=-C K+C A K Z+B K Z-D Z \\
& \frac{\partial K E}{\partial t}=C K+C A K Z+B K E-D E
\end{aligned}
$$




$$
\begin{aligned}
& \frac{\partial A Z}{\partial t}=-C A-C A K Z+G Z \\
& \frac{\partial A E}{\partial t}=C A-C A K E+G E
\end{aligned}
$$

where the terms on the right-hand side of the above equations have the respective meanings as are given in Appendix A, and are defined as follows:

$$
\begin{aligned}
& C K(m)=-\sum_{\boldsymbol{j}} H_{j} \sum_{\boldsymbol{n}} \psi_{n},{ }^{0} J Z K_{n}, j^{m} \\
& C K=\sum_{m} C K(m)=-\sum_{j} H_{j} \sum_{n} \phi_{n}, j^{0} J Z_{n}, j^{0} \\
& C A K Z=-\sum_{j} \sigma_{j} G_{j} \sum_{n} T_{n}, j^{0} \omega_{n}, j^{0} \\
& C A K(m)=-\sum_{j} \sigma_{j} G_{j} \sum_{n} 2 \operatorname{Re}\left\{\omega_{n},{ }^{m} T_{n},{ }_{j}{ }^{m *}\right\} \\
& C A K E=\sum_{m} C A K(m) \\
& B K Z=-H_{1} \sum_{n} n(n+1) \psi_{n}, j^{0} \\
& \times\left(c_{n},{ }_{1}^{0} \omega_{n-1}, 0^{0}+c_{n+1}, 1^{0} \omega_{n+1}, 0^{0}\right) \\
& B K(m)=-H_{1} \sum_{n} 2 n(n+1) \\
& \times \operatorname{Re}\left\{\phi_{n},{ }_{1}{ }^{m *}\left(c_{n},{ }_{1}{ }^{m} \omega_{n-1}, 0^{m}\right.\right. \\
& \left.\left.+c_{n+1},{ }_{1}^{m} \omega_{n+1}, 0^{m}\right)\right\} \\
& B K E=\sum_{m} B K(m) \\
& D Z=\sum_{n} H_{j} \sum_{j} n(n+1) \phi_{n, j^{0}} \\
& \times\left[k_{j}\left(\phi_{n, j^{0}}-\phi_{n, j-2^{0}}\right)\right. \\
& \left.+k_{j}{ }^{\prime}\left(\psi_{n, j^{0}}-\phi_{n, j+2^{0}}\right)+d_{n}{ }^{0} \psi_{\left.n, j^{0}\right]}\right] \\
& D(m)=\sum_{j} H_{j} \sum_{n} 2 n(n+1) R e \\
& \times\left\{\phi_{n}, j^{m *}\left[k_{j}\left(\phi_{n, j^{m}}-\phi_{n, j_{-2}{ }^{m}}\right)\right.\right. \\
& \left.\left.+k_{j}{ }^{\prime}\left(\phi_{n, j^{m}}-\phi_{n, j_{+2}{ }^{m}}\right)+d_{n}{ }^{m} \psi_{n, j^{m}}\right]\right\} \\
& D E=\sum_{m} D(m) \\
& C A(m)=\sum_{\boldsymbol{j}} \boldsymbol{G}_{j} \sum_{\boldsymbol{n}} \boldsymbol{T}_{n},{ }^{0} J T A_{n},{ }^{m}{ }^{m} \\
& C A=\sum_{m} C A(m)=\sum_{j} G_{j} \sum_{n} T_{n}, j^{0} J T_{n, j^{0}} \\
& G Z=\sum_{j} G_{j} \sum_{n} T_{n}, j^{0}\left(\dot{Q}_{n}, j^{0}-g_{n}{ }^{0} T_{n}, j^{0}\right) \\
& G(m)=\sum_{j} G_{j} \sum_{n} 2 \\
& \times \operatorname{Re}\left\{\boldsymbol{T}_{n},{ }^{m *}\left(\dot{Q}_{n},{ }^{m}{ }^{m}-\boldsymbol{g}_{n}{ }^{m} \boldsymbol{T}_{n},{ }^{m}\right)\right\} \\
& G E=\sum_{m} G(m)
\end{aligned}
$$

where $k_{j}, k_{j}{ }^{\prime}, c_{n}, j^{m} d_{n}{ }^{m}$ and $g_{n}{ }^{m}$ are givenin the text,

$\operatorname{Re}\{\}=$ real part of the quantity in \{\}, ()$^{*}=$ complex conjugate of the quantity in the parenthesis ( ),

$$
J Z_{n, j^{0}}=\sum_{m} J Z K_{n, j^{m}},
$$

and

$$
J T_{n, j^{0}}=\sum_{m} J T A_{n, j^{m}} .
$$

The above equations can be easily extended to those in the spectral wavenumber domain. The added terms are the non-linear energy exchange terms in the kinetic and available potential energy equations as follows:

$$
\begin{aligned}
& L K(m)=\sum_{j} H_{j} \sum_{n} 2 \operatorname{Re}\left\{\phi_{n},{ }^{m *} J Z_{n}, j^{m}\right\} \\
& L A(m)=\sum_{j} G_{j} \sum_{n} 2 \operatorname{Re}\left\{\boldsymbol{T}_{n}, j^{m *} J T_{n}, j^{m}\right\} .
\end{aligned}
$$

\section{Appendix C: Dependence on value of vertical eddy viscosity coefficient}

As stated in the text, the eddy activity and the meridional circulation may depend on the vertical eddy viscosity coefficient $\mu$. Here, for the sake of comparison, we assume $\mu=0$, and perform an integration of the model up to 300 model days, starting from the same initial condition as the case $\mu \neq 0$ (see Fig. 4). The time change of the total, available potential and kinetic energies are given in Fig. C-1. In comparison with the case $\mu \neq 0$, the following differences are seen: Appreciable energy fluctuations occur three times with a period of about 25 days, a quasi-steady state is attained after 200 model days, and the energy levels of the kinetic energy and the total energy at the final stage are larger than those in the case $\mu \neq 0$. From the energy flow diagram Fig. C-2, it is also seen that the magnitudes of the disturbances are larger than those in the case $\mu \neq 0$. The three cell pattern is thus more clearly seen in Fig. C-3 than Fig. 4 regarding the latitudeheight distribution of the zonal mean fields.

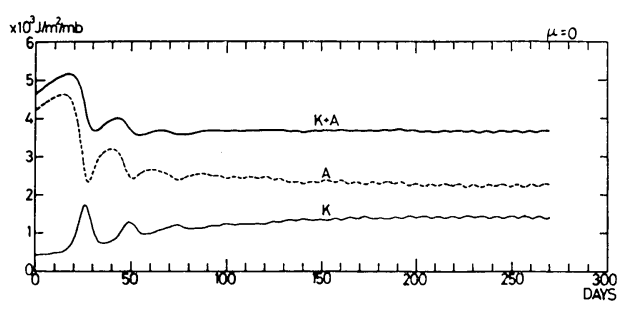

Fig. C-1 Time variation of total $(\mathrm{K}+\mathrm{A})$, available potential (A) and kinetic (K) energies during the course of numerical integration in the case of $\mu=0$. 


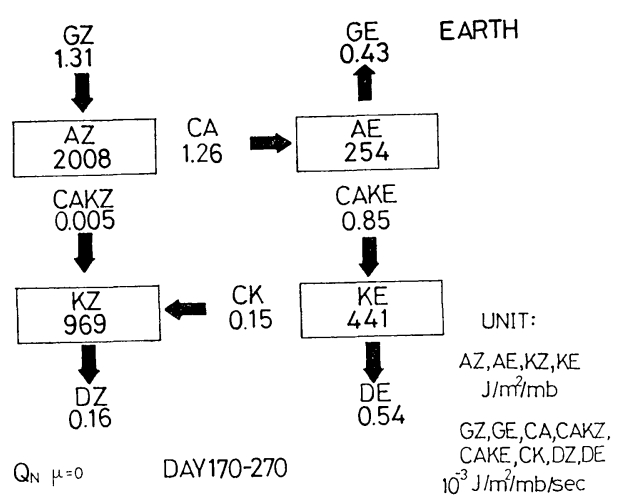

Fig. C-2 Energy flow diagram for the quasisteady state averaged over the period from the day 170 to 270 .
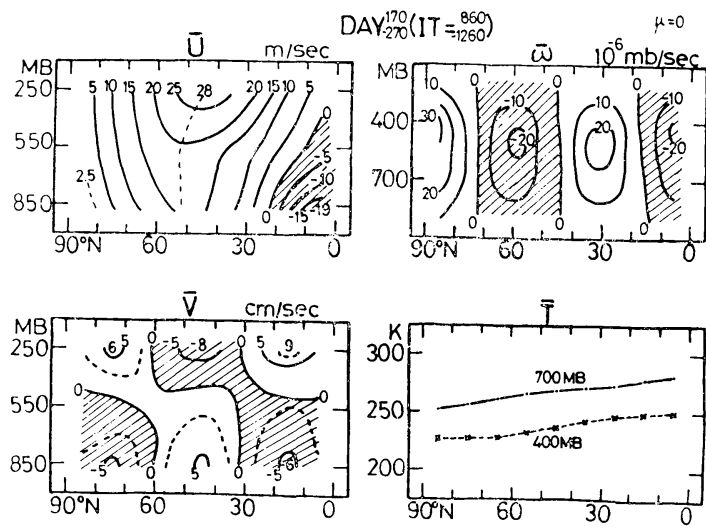

Fig. C-3 Latitude-height distribution of the zonal mean fields for the QS state in the case $\mu=0$.

\section{References}

Arakawa, A., 1957: On the mean meridional circulation in the atmosphere. J. Meteor. Soc. Japan, 75th Anniversary Volume, 230-236.

Clark, J. H. E., 1970: A quasi-geostrophic model of the winter stratospheric circulation. Mon. Wea. Rev., 98, 443-461.

COESA, U.S. Committee on Extension to the Standard Atmosphere, 1966: U.S. Standard Atmosphere Supplements, 1966. U.S. Government Printing Office, Washington, D.C., 289 pp.

Eliasen, E., B. Machenhauer and E. Rasmussen, 1970: On a numerical method for integration of the hydrodynamical equations with a spectral representation of the horizontal fields. Institute of Theoretical Meteorology, University of Copenhagen, Report No. 2.

Hunt, B. G., 1974: A global general circulation model of the atmosphere based on the semi-spectral method. Mon. Wea. Rev., 102, 3-16.
Kikuchi, Y., 1969: Numerical simulation of the blocking process. J. Meteor. Soc. Japan, 47, 2954.

Lorenz, E. N., 1960: Energy and numerical weather prediction. Tellus, 12, 364-373.

Manabe, S. and F. Möller, 1961: On the radiative equilibrium and heat balance of the atmosphere. Mon. Wea. Rev., 89, 503-532.

Oort, A. H. and E. M. Rasmusson, 1971: Atmospheric circulation statistics. NOAA Professional Paper, 5, 323 pp.

Orszag, S. A., 1970: Transform method for calculation of vector coupled sums: Application to the spectral form of the vorticity equation. $J$. Atmos. Sci., 2\%, 890-895.

Peixoto, J. P. and A. H. Oort, 1974: The annual distribution of atmospheric energy on a planetary scale. J. Geophys. Res., 79, 2149-2159.

Peng, L., 1965: A simple numerical experiment concerning the general circulation in the lower stratosphere. Pure Appl. Geophys., 61, 191-218.

Phillips, N., 1954: Energy transformations and meridional circulations associated with simple baroclinic waves in a two-level, quasi-geostrophic model. Tellus, 6, 273-286.

, 1959: Numerical integration of the primitive equations on the hemisphere. Mon. Wea. Rev., 87, 333-345.

Robert, A. J., 1966: The integration of a low order spectral form of the primitive meteorological equations. J. Meteor. Soc. Japan, 44, 237-245.

Searle, J. W. and D. R. Davies, 1975: The sensitivity of dependence of large scale flow characteristics in a four-level model atmosphere on a simulated planetary boundary layer. Tellus, 27, 145-154.

Simmons, A. J. and B. J. Hoskins, 1978: The life cycles of some nonlinear baroclinic waves. $J$. Atmos. Sci., 35, 414-432.

Simons, T. J. and D. B. Rao, 1972: Nonlinear interaction of waves and zonal current in a two-layer baroclinic model. Tellus, 24, 1-5.

Stone, P. H., W. J. Quirk and R. C. J. Somerville, 1974: The effect of small-scale vertical mixing of horizontal momentum in a general circulation model. Mon. Wea. Rev., 102, 765-771.

Tenenbaum, J., 1976: Spectral and spatial energetics of the GISS model atmosphere. Mon. Wea. Rev., 104, 15-30.

Trenberth, K. E., 1973: Global model of the general circulation of the atmosphere below 75 kilometers with annual heating cycle. Mon. Wea. Rev., 101, 287-305.

Wiin-Nielsen, A., J. A. Brown and M. Drake, 1964: Further studies of energy exchange between the zonal flow and the eddies. Tellus, 16, 168-180. and J. Sela, 1971: On the transport of quasi-geostrophic potential vorticity. Mon. Wea. Rev., 99, 447-468. 


\section{スペクトル大気大循環モデル}

\section{I. 地球大気に対する予備的時間積分}

\section{岩 嶋樹也*・森 山 茂**・山元龍三郎*}

* 京都大学理学部地球物理学教室

** 日本大学生産工学部習志野校舎物理教室

気候および大気大循環（地球のみならず他の惑星を含む）に関する広範な問題を研究するためには，取扱いの容易 かつ簡単な従って計算時間等の面で，より経済的なモデルが必要であり，またそれは有力な手段でもある。そのよう なモデルの作成が我々の目標である。

スペクトルー格子点法を用いた三層線型バランス大気大循環スペクトルモデルを提示し，簡単な予備計算を行い， 安定に長時間計算を進められることを示した。結果は観測拉よび他の研究者によるモデル計算と比較検討された。結 果の検討は, 主として東西平均場拉よび各種エネルギーとその変換・輸送量の時間変化や平衡状態に扣ける運動量・ 顕熱南北輸送について行なった。今回のモデルには，超長波の生成維持に重要とされている大規模地形や冷熱源に関 する効果を取り入れていない。モデルの範囲内では充分妥当と思われる結果が得られた。さらに大気大循環をシミュ レートするに充分な，また精巧なモデルにするためには，上記の非断熱効果や各種パラメータ（あるいは，種々の物 理過程のパラメタリゼーション) の，より適切な取扱いについての検討が必要であり，また課題である。 